\title{
Clinical features and lifestyle of patients with amyotrophic lateral sclerosis in Campania: brief overview of an Italian database
}

\author{
Francesca Trojsi ${ }^{(a, b)}$, Anna Sagnelli(a,b), Nicola Vanacore ${ }^{(\mathrm{c})}$, Giovanni Piccirillo $^{(\mathrm{a}, \mathrm{b})}$, Luca Daniele $^{(\mathrm{a}, \mathrm{b})}$, \\ Francesco Izzo $^{(\mathrm{a})}$, Anna Laiola ${ }^{(\mathrm{a})}$, Alfonso Di Costanzo( ${ }^{(\mathrm{b}, \mathrm{d})}$, Giovanni Savettieri(e), \\ Maria Rosaria Monsurrò ${ }^{(a, b)}$ and Gioacchino Tedeschi ${ }^{(a, b)}$ \\ (a) Dipartimento di Scienze Neurologiche, Seconda Università degli Studi di Napoli, Naples, Italy \\ (b) Centro di Alti Studi di Risonanza Magnetica, \\ Fondazione Italiana Sclerosi Multipla (FISM), Naples, Italy \\ (c) Centro Nazionale di Epidemiologia, Istituto Superiore di Sanità, Rome, Italy \\ (d) Dipartimento di Scienze della Salute, Università del Molise, Campobasso, Italy \\ (e) Dipartimento di Neuroscienze Cliniche, Università di Palermo, Palermo, Italy
}

\begin{abstract}
Background. Physical activity and occupational exposures appeared to play a relevant role in pathogenesis of amyotrophic lateral sclerosis (ALS), a neurodegenerative disease of unknown origin. Materials and methods. We aimed to make an overview of the clinical characteristics and lifestyle (occupation and sport) of a population of 395 patients with ALS from Campania, in southern Italy. Results. ALS onset resulted anticipated of about 11 years in industry workers, whilst the more frequent site of onset among farmers was upper limbs. Compared to non-athletes, athletes, particularly soccer players, showed a 7 years anticipation of ALS onset, with higher mortality after 5 years. Discussion and conclusions. We suggest that subjects genetically prone to abnormal response to hypoxia during strenuous physical activity or exposed to neurotoxic agents, such as athletes, farmers or industry workers, might present increased risk to develop ALS. Future case-control and follow-up studies on our population should be implemented to deepen the present results.
\end{abstract}

Key words: amyotrophic lateral sclerosis, motor neuron diseases, clinical database, occupational exposure.

\begin{abstract}
Riassunto (Caratteristiche cliniche e stile di vita di pazienti con sclerosi laterale amiotrofica in Campania: breve panoramica di un database italiano). Introduzione. Attività fisica ed esposizione professionale a sostanze tossiche sembrano svolgere un ruolo rilevante nella patogenesi della sclerosi laterale amiotrofica (SLA), una malattia neurodegenerativa di origine sconosciuta. Materiali e metodi. Ci siamo proposti di effettuare una panoramica delle caratteristiche cliniche e dello stile di vita (attività lavorativa e sport) di una popolazione di 395 pazienti affetti da SLA provenienti dalla regione Campania, in Italia meridionale. Risultati. L'insorgenza della SLA è risultata anticipata di circa 11 anni nei lavoratori dell'industria, mentre il sito più frequente di insorgenza tra i contadini era caratterizzato dagli arti superiori. Rispetto ai nonsportivi, gli sportivi, soprattutto i calciatori, hanno mostrato un'anticipazione di 7 anni nell'insorgenza della SLA, con maggiore mortalità a 5 anni. Discussione e conclusioni. Abbiamo ipotizzato che i soggetti geneticamente predisposti a risposte anomale all'ipossia durante l'attività fisica intensa o esposti ad agenti neurotossici, come gli sportivi, gli agricoltori o i lavoratori dell'industria, possano presentare un aumentato rischio di sviluppare la SLA. Futuri studi caso-controllo e di follow-up sulla nostra popolazione dovrebbero essere effettuati per approfondire i risultati attuali.
\end{abstract}

Parole chiave: sclerosi laterale amiotrofica, malattie del motoneurone, database clinico, esposizione occupazionale.

\section{INTRODUCTION}

Amyotrophic lateral sclerosis (ALS) is a degenerative disease involving motor neurons. Incidence of ALS varies from 0.6 to 2.6 cases per 100000 population/year, however in the 1990's the incidence of the sporadic form (SALS) has been reported to be between 1.5 and 2.7/100 000 population/year in Europe and North America [1]. Populationbased studies, often drawing data from population registries implemented in several countries for this purpose, have been useful in defining epidemiological, clinical and prognostic characteristics of ALS [2].

The cause of ALS is unknown, although some environmental and genetic risk factors have been identified. Several hypotheses have been proposed in an effort to find a relationship with a number of exogenous risk factors, such as physical activity, traumatisms, and exposure to toxic substances, alone or in association with genetic predisposing features [3-6]. 
In this study we briefly depicted clinical characteristics and lifestyle habits (i.e. occupational toxic exposure and sports) of a large population of ALS patients from Campania, a region in southern Italy.

\section{MATERIALS AND METHODS}

We revised the records of 395 ALS cases (202 M, $193 \mathrm{~F}$ ), registered in our data base, fulfilling the diagnostic criteria for possible, probable or definite ALS, according to the revised El Escorial criteria of the World Federation of Neurology [7], followed between 1990 and 2009 by the ALS Centre of the Department of Neurological Sciences of the Second University of Naples (Italy).

The collected data regarded clinical forms, age at onset of the first symptoms, disease duration, family history, municipalities of residency in the last 10 years, occupation, and sport. All patients were treated with riluzole for at least six months.

Clinical and lifestyle features (i.e. type of occupation and sport) were more accurately assessed in 102 patients (58 M, $44 \mathrm{~F}$, mean age 57.8), recruited consecutively between 2002 and 2006 and systematically submitted to an ad hoc questionnaire. A detailed history of each employment was collected, including job description, date of commencement and cessation, and type and degree of physical activity. The occupation held for the longest period of time before the disease onset was extracted for each patient and considered to be the main occupation. All occupations were coded according to the most recently updated version of the international standard classification of occupations (ISCO-08) adopted by the International Labor Organization (ILO), a United Nations specialized agency. According to this system, jobs were classified in ten major occupa- tional groups: managers; professionals; technicians and associate professionals; clerical support workers; service and sales workers; skilled agricultural, forestry and fishery workers; craft and related trades workers; plant and machine operators, and assemblers; elementary occupations; armed forces occupations.

Detailed information was also collected on each sport, including type, degree of physical activity required, date of commencement and cessation, and hours per week of physical activity. Sportspeople were classified as amateur (about 150 minutes of moderate physical activity per week, according to recommendations of World Health Organization on "physical activity for health" [8], for at least 5 years), organized (more than 150 minutes per week by more than 5 years) or professional (i.e. athletes engaged by professional teams or coaches). Records were also reviewed for drug exposure (limited to compounds taken for at least six months).

Clinical variables were examined using non parametric tests by the SPSS software. Between group variability was evaluated with the Mann-Whitney test, and associations between clinical features and lifestyle habits were established with the $\chi_{2}$ test. P values $<0.05$ were considered statistically significant after correction for multiple comparisons with the Bonferroni method.

\section{RESULTS}

In our ALS population, mean age at onset was $57+$ 12 years, with males/females ratio of 1.04 . We found an higher frequency of cases with lower limbs onset (38\%), compared to cases with upper limbs onset $(32 \%)$ and bulbar onset (27\%). The different clinical forms of ALS were subdivided as shown in Table 1.

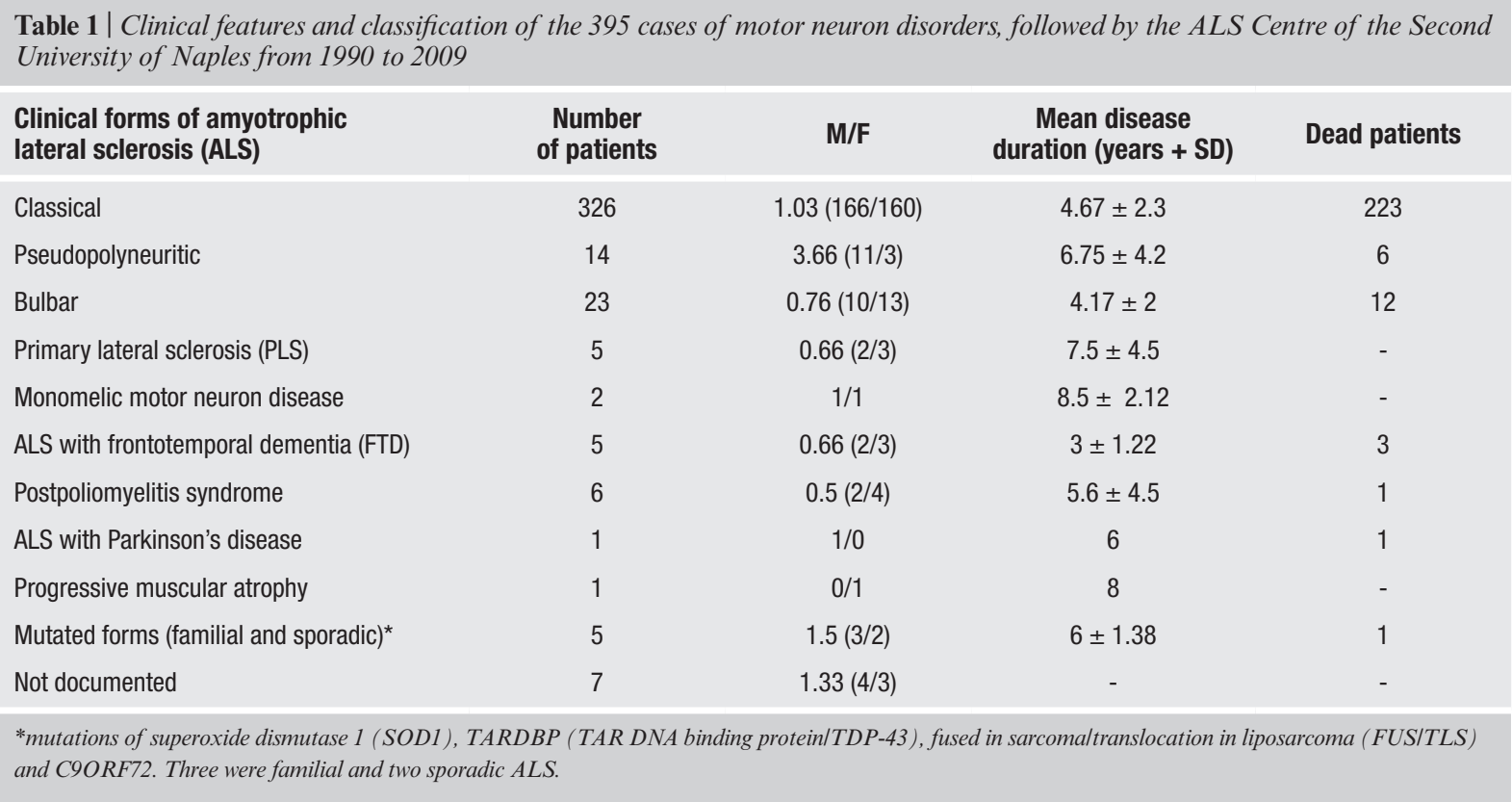




\begin{tabular}{|c|c|c|c|c|c|c|}
\hline $\begin{array}{l}\text { ISC0-08 major } \\
\text { groups of jobs }\end{array}$ & $\begin{array}{c}\text { Number of } \\
\text { patients } \\
(\%)\end{array}$ & $\begin{array}{c}\text { Mean age at } \\
\text { onset } \\
\text { (+SD) }\end{array}$ & $\begin{array}{l}\text { Mean disease } \\
\text { duration } \\
\text { (years) }\end{array}$ & $\begin{array}{l}\text { Upper limbs } \\
\text { onsets } \\
\text { n. (\%) }\end{array}$ & $\begin{array}{l}\text { Lower limbs } \\
\text { onsets } \\
\text { n. (\%) }\end{array}$ & $\begin{array}{l}\text { Bulbar } \\
\text { onsets } \\
\text { n. (\%) }\end{array}$ \\
\hline Managers & $12(11.8)$ & $57.6 \pm 6.3$ & $5.37 \pm 3.8$ & $3(25)$ & $7(58.3)$ & $2(16.7)$ \\
\hline Professionals & $10(9.8)$ & $60.5 \pm 4.3$ & $4.67 \pm 2.3$ & $4(40)$ & $3(30)$ & $3(30)$ \\
\hline Technicians and associate professionals & $13(12.7)$ & $55.9 \pm 8.6$ & $3.8 \pm 6.3$ & $5(38.5)$ & $5(38.5)$ & $3(23)$ \\
\hline Clerical support workers & $3(2.9)$ & $61.6 \pm 6.4$ & $5.17+2$ & $1(33.3)$ & $2(66.7)$ & - \\
\hline Service and sales workers & $21(20.6)$ & $56.2 \pm 5.4$ & $4.6 \pm 4.5$ & $8(38)$ & $11(52.3)$ & $2(9.6)$ \\
\hline Skilled agricultural, forestry and fishery workers & $12(11.8)$ & $63.6 \pm 7.2$ & $3.3 \pm 4.2$ & $7(58.3)$ & $4(33.3)$ & $1(8.4)$ \\
\hline Craft and related trades workers & $7(6.9)$ & $57.6 \pm 4.5$ & $3.4 \pm 5.3$ & $3(42.8)$ & $3(42.8)$ & $1(14.2)$ \\
\hline Plant and machine operators, and assemblers & $12(11.8)$ & $52.6 \pm 8.3$ & $4.2 \pm 3.5$ & $5(41.6)$ & $5(41.6)$ & $2(16.6)$ \\
\hline Elementary occupations & $11(10.8)$ & $56.4 \pm 7.2$ & $5.6 \pm 4.5$ & $3(27.2)$ & $4(36.4)$ & $4(36.4)$ \\
\hline Armed forces occupations & $1(0.9)$ & 56 & 6.5 & - & 1 & - \\
\hline
\end{tabular}

All 395 patients, except $15(4 \%)$ living in other regions and $29(7 \%)$ not documented, were distributed in the different municipalities of the five administrative districts of Campania as follows: 229 (58\%) from Naples, 52 (13\%) from Caserta, 41 (10\%) from Salerno, $17(4 \%)$ from Avellino, $13(3 \%)$ from Benevento.

The patients with ALS and frontotemporal dementia (ALS-FTD) had the worst prognosis, whereas the ALS patients with pseudopolyneuritic form $(11 \mathrm{M}, 3 \mathrm{~F})$, primary lateral sclerosis (PLS) $(2 \mathrm{M}, 3 \mathrm{~F})$, monomelic motor neuron disease $(1 \mathrm{M}, 1 \mathrm{~F})$ and progressive muscular atrophy $(1 \mathrm{~F})$ had disease duration greater than 5 years.

Percutaneous endoscopic gastrostomy (PEG) was inserted in $38 \%$ of all cases. Dysphagic spinal-onset patients with PEG lived longer than those who refused this palliative care (44 months vs 36 months). Among bulbar-onset patients, PEG users showed a median survival time longer than those with no PEG (28 months vs 25 months). Non invasive ventilation was instituted in 190 patients (48\%). Fifteen patients $(4 \%)$ chose invasive ventilation with a tracheostomy, whilst 30 patients $(8 \%)$ who were unable to decide for or against tracheostomy received invasive ventilation on emergency basis due to respiratory failure. The median survival time after tracheostomy was 8 months.

Regarding occupation, we collected the clinical features of 102 patients consecutively and systematically followed from 2002 to 2006 for lifestyle information and subdivided in ten major groups of jobs (Table 2), comparing the clinical characteristics of plant and machine operators to those of skilled agricultural and forestry workers (both groups have been associated with occupational exposure to neurotoxic chemicals, probably involved in the neurodegeneration of motor neurons $[5,6])$. The mean age at onset was significantly lower (about 11 years) for industry operators $(52.6 \pm 8.3$ years $)$ compared to agricultural workers $(63.6 \pm 7.2$ years) $(\mathrm{p}<0.05)$, but there was a difference of about 1 year in the mean disease duration in these two groups, with a longer survival in industry operators (Table 2). The upper limbs onset was more frequent among skilled agricultural and forestry workers $(58.3 \%)$.

Regarding sports, the 52 patients were classified in: 30 amateur $(18 \mathrm{M}, 12 \mathrm{~F}), 14$ organized $(8 \mathrm{M}, 6$ F) and 8 professional $(6 \mathrm{M}, 2 \mathrm{~F})$. An anticipation of disease onset of about 7 years was observed in all sporty patients $(48.1 \pm 9.5$ years $)$ compared to nonsporty patients ( $55.8 \pm 8.5$ years). Moreover, the age of onset was further reduced when considering only patients who played soccer $(45.3 \pm 11.5$ years $)$ (30 $\mathrm{M}, 2 \mathrm{~F}$ ), compared to non-sporty patients (age and sex matched $)(p<0.05)$.

The percentage of lower limb onset among patients who practiced organized and professional sports was nearly twice $(58 \%)$ compared with non-sporty patients $(30 \%)$ (age and sex matched) $(\mathrm{p}<0.05)$.

Mean disease duration and drug exposure showed no significant differences between sporty people and non-sporty patients. However, mortality was $100 \%$ at 5 years among patients who practiced organized and professional sports (mean disease duration was $3.6 \pm 1.4$ years), whereas 13 non-sporty patients $(25 \%)$ had an history of illness lasting more than 5 years (mean disease duration was $5.8 \pm 0.6$ years).

\section{DISCUSSION}

The epidemiological characteristics of ALS remain uncertain, despite the large number of studies performed in the last three decades. In our monocentric experience, the disease duration presented a variability that reproduced what is already known [9], with rare cases of patients with long survival (about 4\%) and more frequent death after 5-10 years of disease. About the site of symptoms' onset, limbs 
onset was the most common (70\%) and the frequency of bulbar presentation $(27 \%)$ resulted close to the frequency found in northern Italy (Piemonte/Valle D'Aosta and Lombardy) (31\%) [10].

The analysis of our database did not allow to estimate the exposure to environmental and individual supposed risk factors or to identify predominant categories of workers at risk, essentially because it is not a case-control study. Rather, we intended only to make an overview of a single ALS Center experience to derive potentially interesting research ideas for future case-control and multi-centric studies. Although our findings from the group of 102 ALS patients may be hampered by the inclusion procedure of a restricted group of patients, we believe that this sample of patients, consecutively followed between 2002 and 2006, might be representative of the entire population, and the selection bias could be considered fairly low.

The anticipation of mean age of ALS onset in plant and machine operators might suggest a possible role played by workplace exposure to toxic agents, especially metals, lubricating oils, antifreeze or coolants, or dry cleaning agents, according to other previously reported data $[4,6]$.

The upper limbs onset was much more common in skilled agricultural and forestry workers $(58.3 \%)$, indicating that probably a very intense manual labour might support the onset of the disease [11]. Although toxic etiopathogenesis has not yet been clarified in ALS, one might hypothesize a possible synergistic effect between the toxicity of various substances, such as pesticides [3, 5, 6], physical activity [11] or hypoxia [12], and the neurodegenerative process.

Our preliminary data about sport further support previous evidences on correlation between ALS and physical activity, particularly for soccer [11, 13, 14], where an absolute increased risk of developing ALS or an anticipation effect have been reported.

\section{References}

1. Worms PM. The epidemiology of motor neuron diseases: a review of recent studies. J Neurol Sci 2001;191:3-9. http://dx.doi.org/10.1016/S0022-510X(01)00630-X

2. Beghi E, Logroscino G, Chiò A, Hardiman O, Mitchell D, Swingler R, Traynor BJ, EURALS Consortium. The epidemiology of ALS and the role of population-based registries. Biochim Biophys Acta 2006;1762:1150-7. http://dx.doi.org/10.1016/j.bbadis.2006.09.008

3. Qureshi MM, Hayden D, Urbinelli L, Ferrante K, Newhall K, Myers D, Hilgenberg S, Smart R, Brown RH, Cudkowicz ME. Analysis of factors that modify susceptibility and rate of progression in amyotrophic lateral sclerosis (ALS). Amyotroph Lateral Scler 2006;7:173-82. http://dx.doi.org/10.1080/14660820600640596

4. Vinceti M, Bonvicini F, Bergomi M, Malagoli C. Possible involvement of overexposure to environmental selenium in the etiology of amyotrophic lateral sclerosis: a short review. Ann Ist Super Sanità 2010;46:279-83. http://dx.doi.org/10.4415/ANN_10_03_09

5. Bonvicini F, Marcello N, Mandrioli J, Pietrini V, Vinceti M.
The evidence of more frequent lower limbs onset in organized and professional sporty patients, although in disagreement with recent results reporting higher prevalence of bulbar onset in soccer players [14], might support the theory of an increased susceptibility to micro-traumatism damage of longer axons [13]. There are few data about a different pathogenesis of ALS according to the site of onset: a recent genome-wide genotyping study has found different genetic linkages in bulbar and spinal patients, underlining the role of some predisposing genes, together with environmental factors, in triggering different sporadic ALS phenotypes [15]. Moreover, intense physical activity would facilitate further biomolecular mechanisms of oxidative stress, with massive formation of reactive oxygen species [13]. The association between toxic exposure and soccer in ALS refers to the diffuse use of chemicals agents, such as herbicides and pesticides in soccer fields, as 2,4-dichlorophenoxyacetic acid [5,13], found in the island of Guam, where ALS is endemic.

In conclusion, our experience might suggest the hypothesis that environmental factors are involved in the pathogenesis of ALS. However, more systematic studies are needed to test whether and how the genetic pathways associated with motoneuron degeneration can potentially interact with environmental toxicants and contribute to development of ALS.

\section{Acknowledgements}

We thank Fabrizio Esposito, for his accurate manuscript review. This study was supported by a training grant from Italian Amyotrophic Lateral Sclerosis Association (AISLA).

\section{Conflict of interest statement}

The authors disclosure no conflicts of interest.

Received on 30 April 2012.

Accepted on 25 June 2012.
Exposure to pesticides and risk of amyotrophic lateral sclerosis: a population-based case-control study. Ann Ist Super Sanità 2010;46:284-7.

http://dx.doi.org/10.4415/ANN_10_03_10

6. Sutedja NA, Veldink JH, Fischer K, Kromhout H, Heederik D, Huisman MH, Wokke JH, Van Den Berg LH. Exposure to chemicals and metals and risk of amyotrophic lateral sclerosis: a systematic review. Amyotroph Lateral Scler 2008;8:1-20. http://dx.doi.org/10.3109/17482960802455416

7. Brooks BR, Miller RG, Swash M, Munsat TL, World Federation of Neurology Research Group on Motor Neuron Diseases. El Escorial revisited: revised criteria for the diagnosis of amyotrophic lateral sclerosis. Amyotroph Lateral Scler Other Motor Neuron Disord 2000;1:293-9.

http://dx.doi.org/10.1080/146608200300079536

8. WHO. Global Recommendations on Physical Activity for Health. Geneva: World Health Organization; 2010.

9. Leigh PN. Amyotrophic lateral sclerosis. In: Eisen AA, Shaw PJ (Ed.). Motor neuron disorders and related disease, $3^{\text {rd }}$ Series. Amsterdam: Elsevier; 2007. p. 249-78. 
10. Chiò A, Mora G, Leone M, Mazzini L, Cocito D, Giordana MT, Bottacchi E, Mutani R, Piemonte and Valle d'Aosta Register for ALS (PARALS). Early symptom progression rate is related to ALS outcome: a prospective populationbased study. Neurology 2002;59:99-103. http://dx.doi.org/10.1212/WNL.59.1.99

11. Beghi E, Logroscino G, Chiò A, Hardiman O, Millul A, Mitchell D, Swingler R, Traynor BJ. Amyotrophic lateral sclerosis, physical exercise, trauma and sports: results of a population-based pilot case-control study. Amyotroph Lateral Scler 2010;11:289-92.

http://dx.doi.org/10.3109/17482960903384283

12. Vanacore N, Cocco P, Fadda D, Dosemeci M. Job strain, hypoxia and risk of amyotrophic lateral sclerosis: results from a death certificate study. Amyotroph Lateral Scler 2010;11:430-4. http://dx.doi.org/10.3109/17482961003605796
13. Beretta S, Carrì MT, Beghi E, Chiò A, Ferrarese C. The sinister side of Italian soccer. Lancet Neurology 2003;2:656-7. http://dx.doi.org/10.1016/S1474-4422(03)00579-9

14. Chiò A, Calvo A, Dossena M, Ghiglione P, Mutani R, Mora G. ALS in Italian professional soccer players: the risk is still present and could be soccer-specific. Amyotroph Lateral Scler 2009;10:205-9. http://dx.doi.org/10.1080/17482960902721634

15. Schymick JC, Scholz SW, Fung HC, Britton A, Arepalli S, Gibbs JR, Lombardo F, Matarin M, Kasperaviciute D, Hernandez DG, Crews C, Bruijn L, Rothstein J, Mora G, Restagno G, Chiò A, Singleton A, Hardy J, Traynor BJ. Genome-wide genotyping in amyotrophic lateral sclerosis and neurologically normal controls: first stage analysis and public release of data. Lancet Neurol 2007;6:322-8. http://dx.doi.org/10.1016/S1474-4422(07)70037-6 